\title{
Leucopenia and treatment efficacy in advanced nasopharyngeal carcinoma
}

\author{
Zhen $\mathrm{Su}^{1+}$, Yan-Ping Mao ${ }^{1 \dagger}$, Pu-Yun OuYang ${ }^{1}$, Jie Tang ${ }^{1}$, Xiao-Wen Lan ${ }^{1}$ and Fang-Yun Xie ${ }^{1,2^{*}}$
}

\begin{abstract}
Background: Leucopenia or neutropenia during chemotherapy predicts better survival in several cancers. We aimed to assess whether leucopenia could be a biological measure of treatment and a marker of efficacy in advanced nasopharyngeal carcinoma (ANPC).
\end{abstract}

Methods: We retrospectively analyzed 3826 patients with ANPC who received chemoradiotherapy. Leucopenia was categorised on the basis of worst grade during treatment according to the National Cancer Institute Common Toxicity Criteria version 4.0: no leucopenia (grade 0), mild leucopenia (grade 1-2), and severe leucopenia (grade $3-4)$. Associations between leucopenia and survival were estimated by Cox proportional hazards model.

Results: Of the 3826 patients, 2511 (65.6\%) developed mild leucopenia (grade 1-2) and 807 (21.1\%) developed severe leucopenia (grade 3-4) during treatment; 508 (13.3\%) did not. A multivariate Cox model that included leucopenia determined that the hazard ratios (HR) of death for patients with mild and severe leucopenia were 0.69 [95\% confidence interval $(95 \% \mathrm{Cl}) 0.56-0.85, p<0.001$ ] and $0.75(95 \% \mathrm{Cl} 0.59-0.95, p=0.019)$, respectively; the HR of distant metastasis for patients with mild and severe leucopenia were $0.77(95 \% \mathrm{Cl} 0.61-0.96, p=0.023)$ and 0.99 (95\%Cl 0.77-1.29, $p=0.995$ ), respectively. Leucopenia had no effect on locoregional relapse.

Conclusions: Our results indicate that mild leucopenia during chemoradiotherapy is associated with improved overall survival and distant metastasis-free survival in ANPC. Mild leucopenia may indicate appropriate dosage of chemotherapy. We can identify the patients who may benefit from chemotherapy if they experienced leucopenia during the treatment. Prospective trials are required to assess whether dosing adjustments based on leucopenia may improve chemotherapy efficacy.

Keywords: Leucopenia, Advanced nasopharyngeal carcinoma, Chemoradiotherapy, Survival, Treatment efficacy

\section{Background}

Nasopharyngeal carcinoma (NPC) is a distinct type of head and neck cancer. The incidence rate is as high as 20-30 per 100,000 populations in endemic areas of southern China and Southeast Asia [1-3]. Radiotherapy (RT) is the primary treatment, plus chemotherapy when needed according to clinical stage. With the development of diagnostic imaging, chemotherapy regimens, targeted drugs, and radiotherapeutic techniques, especially the application of IMRT (Intensity Modulated

\footnotetext{
* Correspondence: xiefy0758@sina.com

${ }^{\dagger}$ Equal contributors

'Sun Yat-sen University Cancer Center, State Key Laboratory of Oncology in South China, Collaborative Innovation Center for Cancer Medicine,

Guangzhou 510060, China

${ }^{2}$ Department of Radiation Oncology, Sun Yat-sen University Cancer Center; State Key Laboratory of Oncology in South China; Collaborative Innovation Center for Cancer Medicine, Guangzhou 510060, China
}

Radiation Therapy), survival of NPC has improved significantly [4-6]. However, $10-20 \%$ of patients with advanced NPC (ANPC) develop distant metastasis after radical chemoradiotherapy, rendering distant metastases the main reason for treatment failure. To reduce the occurrence of distant metastasis, different timings of chemotherapy is recommended for ANPC according to NCCN (National Comprehensive Cancer Network) guidelines [7]. In 2014 version of NCCN guidelines, the categories of evidence for induction or adjuvant chemotherapy of NPC has changed [7]. Category of induction chemotherapy of NPC changed from category 2A to category 3. Category of adjuvant chemotherapy "cisplatin + RT followed by cisplatin/5-FU changed from category 1 to category $2 \mathrm{~A}$ and "cisplatin $+\mathrm{RT}$ followed by carboplatin/5-FU changed from category $2 \mathrm{~A}$ to category $2 \mathrm{~B}$. 
Bone marrow suppression is a common adverse reaction of cytotoxic drugs and could be a biological measure of drug activity and might predict treatment efficacy $[8,9]$. Leucopenia or neutropenia during treatment is a common phenomenon of bone marrow suppression. Some studies reported that leucopenia or neutropenia is a prognostic factor predicting better clinical outcome in several solid tumors, e.g., breast cancer [10-12], colorectal cancer [13, 14], advanced gastric cancer [15-17], lung cancer [18-20], and Hodgkin's lymphoma [21]. Others have reported different results [22, 23]. However, the predictive (ie, estimation of the chance of benefit from chemotherapy) or prognostic (ie, estimation of the chance of survival) role of leucopenia in advanced nasopharyngeal carcinoma have not been established.

We aimed to investigate the association between leucopenia during treatment and survival of ANPC and to provide evidences, through rigorous statistical analysis of a large series of subjects with ANPC, of the utility of leukocyte count as a surrogate marker of drug efficacy.

\section{Methods}

\section{Patients and methods}

We retrospectively collected 3939 newly diagnosed ANPC patients from January 2005 to December 2010 treated in the Nasopharyngeal Carcinoma Department of Sun Yat-Sen University Cancer Center. 113 paitents were excluded owing to different reasons, abnormal liver function, abnormal kidney function, unsatisfactory blood sugar control and so on. 3826 patients were involved in the study. The Sun Yat-Sen University Cancer Center Institutional Review Board (IRB) and ethics committee reviewed and approved the study. The study was retrospective. Patient records were anonymized and de-identified prior to analysis.

Pretreatment evaluation included complete patient history, physical examination, hematology and biochemistry profiles, nasopharynx and neck magnetic resonance imaging (MRI), chest radiography, abdominal ultrasound, bone emission computed tomography (ECT), and chest or abdomen computed tomography $(\mathrm{CT})$ when necessary.

\section{Treatment}

The treatment strategy for all patients was based on $\mathrm{Na}$ tional Comprehensive Cancer Network Guidelines [24, 25]. All patients were treated with intensity-modulated RT (IMRT) or conventional RT (CRT) with chemotherapy; the radiation techniques and chemotherapy regimens have been described previously $[26,27]$.

\section{Laboratory measurements}

We performed leukocyte and neutrophil counts for all patients within two weeks before therapy and at least once weekly during treatment. The most severe grade of leucopenia was based on the lowest recorded leukocyte count for a given patient between the first day of treatment administration and 1 week after the end of treatment, and was graded according to the National Cancer Institute Common Toxicity Criteria version 4.0. Patients were classified as having no leucopenia (grade 0), mild leucopenia (grade 1-2), and severe leucopenia (grade 3-4). Indications for using granulocyte colony-stimulating factor (G-CSF) were not specified; it was generally used in grade $3-4$ or febrile leucopenia, and was not used for prophylaxis.

\section{Follow-up}

Patients were regularly followed after RT until death or their last follow-up appointment. Clinic visits were scheduled every three months in the first three years, every six months during the fourth to fifth years, and once a year after the fifth year. Patients underwent physical examination and nasopharyngoscopy on each visit. Nasopharynx and neck MRI, chest radiography, abdominal ultrasound, and ECT were performed after RT or according to clinical indications. The follow-up duration was calculated from the first day of therapy to the day of death or the day of last examination.

\section{Statistical analysis}

We estimated the following endpoints (interval to the first defining event): overall survival (OS), locoregional relapse-free survival (LRFS), and distant metastasis-free survival (DMFS). Survival curves were estimated using the Kaplan-Meier method and compared using the logrank test. Multivariate analyses were performed using the Cox proportional hazards model. We used chi-square tests and Kruskal-Wallis $\mathrm{H}$ tests to assess the statistical significance of associations between categorical variables and the three groups. All statistical tests were 2-tailed; $p<0.05$ was considered statistically significant. All tests were conducted using IBM SPSS version 20.0.0 (IBM Corporation, Armonk, NY, USA).

\section{Results}

\section{Patient characteristics}

Table 1 lists the patient characteristics. We studied 3826 patients (2873 male; 953 female). The median age at diagnosis for male patients was 46 years (range 20-84 years); that for female patients was 44 years (range $20-76$ years). CRT and IMRT were administered to 2583 and 1243 patients, respectively. Induction chemotherapy (IC) was administered to 1073 patients, concurrent chemotherapy (CC) to 1291 patients, IC plus CC (IC + CC) to 1255 patients, and $\mathrm{CC}$ plus adjuvant chemotherapy $(\mathrm{CC}+\mathrm{AC})$ to 207 patients. We administered $<4$ and $\geq 4$ chemotherapy cycles to 2364 (61.8 \%) and 1462 (38.2 \%) patients, respectively. No significant differences were 
Table 1 Patient characteristics according to grade of leucopenia

\begin{tabular}{|c|c|c|c|c|c|}
\hline Variable & All & Absent leucopenia & Mild leucopenia & Severe leucopenia & $P$ value \\
\hline Total & 3826 & $508(13.3)$ & $2511(65.6)$ & $807(21.1)$ & \\
\hline Gender & & & & & $<0.001$ \\
\hline male & 2873(75.1) & $421(82.9)$ & 1936(77.1) & $516(63.9)$ & \\
\hline female & $953(24.9)$ & $87(17.1)$ & $575(22.9)$ & 291(36.1) & \\
\hline Age(years) & & & & & 0.105 \\
\hline$<45$ & 1982(51.8) & $242(47.6)$ & $1325(52.8)$ & $415(51.4)$ & \\
\hline$>=45$ & 1844(48.2) & $266(52.4)$ & $1186(47.2)$ & $392(48.6)$ & \\
\hline Leukocyte count & & & & & $<0.001$ \\
\hline$=<10 \times 10^{\wedge} 9 / \mathrm{L}$ & $3448(90.1)$ & $424(83.5)$ & 2278(90.7) & $746(92.4)$ & \\
\hline$>10 \times 10^{\wedge} 9 / \mathrm{L}$ & $378(9.9)$ & $84(16.5)$ & 233(9.3) & $61(7.6)$ & \\
\hline Pathological type(WHO) & & & & & 0.692 \\
\hline । & $83(2.2)$ & $11(2.2)$ & $55(2.2)$ & $17(2.1)$ & \\
\hline$\|$ & 203(5.3) & $23(4.5)$ & $143(5.7)$ & $37(4.6)$ & \\
\hline III & $3540(92.5)$ & $474(93.3)$ & 2313(92.1) & $753(93.3)$ & \\
\hline T-classification & & & & & 0.720 \\
\hline T1 & $172(4.5)$ & $22(4.3)$ & $109(4.3)$ & $41(5.1)$ & \\
\hline $\mathrm{T} 2$ & $272(7.1)$ & $29(5.7)$ & $185(7.4)$ & $58(7.2)$ & \\
\hline T3 & 1871(48.9) & $271(53.3)$ & $1221(48.6)$ & $379(47.0)$ & \\
\hline T4 & 1511(39.5) & 186(36.6) & 996(39.7) & $329(40.8)$ & \\
\hline N-classification & & & & & 0.09 \\
\hline No & $517(13.5)$ & $86(16.9)$ & $335(13.3)$ & $96(11.9)$ & \\
\hline N1 & 1978(51.7) & $252(49.6)$ & 1313(52.3) & $413(51.2)$ & \\
\hline N2 & 1043(27.3) & 133(26.2) & $680(27.1)$ & $230(28.5)$ & \\
\hline N3 & $288(7.5)$ & $37(7.3)$ & 183(7.3) & 68(8.4) & \\
\hline Clinical stage & & & & & 0.222 \\
\hline III & 2094(54.7) & 295(58.1) & $1369(54.5)$ & 430(53.3) & \\
\hline IV & $1732(45.3)$ & 213(41.9) & $1142(45.5)$ & $377(46.7)$ & \\
\hline Radiotherapy & & & & & 0.004 \\
\hline CRT & $2583(67.5)$ & $329(64.8)$ & $1741(69.3)$ & $513(63.6)$ & \\
\hline IMRT & $1243(32.5)$ & $179(35.2)$ & $770(30.7)$ & 294(36.4) & \\
\hline Chemotherapy & & & & & $<0.001$ \\
\hline IC & 1073(28.0) & 198(39.0) & $697(27.8)$ & $178(22.1)$ & \\
\hline CC & 1291(33.7) & 202(39.8) & 878(35.0) & $211(26.1)$ & \\
\hline $\mathrm{IC}+\mathrm{CC}$ & $1255(32.8)$ & $98(19.3)$ & $804(32.0)$ & $353(43.7)$ & \\
\hline$C C+A C$ & $207(5.4)$ & $10(2.0)$ & $132(5.3)$ & $65(8.1)$ & \\
\hline Paclitaxel & & & & & $<0.001$ \\
\hline NO & $3029(79.2)$ & $403(79.3)$ & $2069(82.4)$ & $557(69.0)$ & \\
\hline YES & 797(20.8) & 105(20.7) & $442(17.6)$ & $250(31.0)$ & \\
\hline Chemotherapy cycles & & & & & $<0.001$ \\
\hline$<4$ & 2364(61.8) & 400(78.7) & $1575(62.7)$ & $389(48.2)$ & \\
\hline$>=4$ & $1462(38.2)$ & $108(21.3)$ & $936(37.3)$ & $418(51.8)$ & \\
\hline
\end{tabular}

Abbreviations: CRT: conventional radiotherapy; IMRT: intensity modulated radiation therapy; IC: Induction chemotherapy; CC: concurrent chemotherapy; AC: adjuvant chemotherapy; WHO: world health organization 
observed for age, $\mathrm{T}$ classification, $\mathrm{N}$ classification, and clinical stage. There were significant differences in pretreatment leukocyte count, type of chemotherapy, chemotherapy cycles, type of RT, sex, and paclitaxel use (yes or no) in the compared groups (all $p<0.05$ ). Patients who developed leucopenia during treatment had lower pretreatment leukocyte counts $(p<0.001)$. More female patients developed leucopenia (female vs. male, $90.1 \%$ vs. $85.3 \%, p<0.001)$; patients using paclitaxel were likely to develop severe leucopenia (31.4\% vs. $18.4 \%, p<0.001$ ).

The median OS was 52.6 months (range 3.07-113.0 months); $10.9 \%$ of patients (417/3826) developed locoregional relapse, $16.5 \%$ (633/3826) developed distant metastases, and $19.0 \%(727 / 3826)$ died. The 5-year OS, LRFS, and DMFS rates for the entire population were $80.70 \%, 87.9 \%$, and $82.1 \%$, respectively.

During treatment, 2511 patients $(65.6 \%)$ developed mild leucopenia (grade 1-2) and 807 patients (21.1\%) developed severe leucopenia (grade 3-4); the remaining $508(13.3 \%)$ did not develop leucopenia.

\section{Survival analyses including leucopenia}

Table 2 shows the univariate analysis of the baseline and clinical characteristics as prognostic factors, including leucopenia. Kaplan-Meier curves according to severity of leucopenia showed that better OS and DMFS were predicted for patients with leucopenia and that leucopenia had no significant effect on LRFS (Fig. 1). The 5-year OS rate in patients with no leucopenia, mild leucopenia, and severe leucopenia was $75.5 \%, 81.9 \%$, and $80.5 \%$, respectively (mild vs no leucopenia, $p=0.001$; severe vs no leucopenia, $p=0.03$; mild vs severe, $p=0.314$ ). The 5 -year DMFS rate in patients with no leucopenia, mild leucopenia, and severe leucopenia was $79.7 \%, 83.7 \%$, and $78.9 \%$, respectively (mild vs. no leucopenia, $p=0.038$; severe vs no leucopenia, $p=0.927$; mild vs severe, $p=0.007$ ). The 5-year LRFS rate in patients with no leucopenia, mild leucopenia, and severe

Table 2 Univariate analysis of survival for patients with ANPC

\begin{tabular}{|c|c|c|c|c|c|c|}
\hline \multirow[b]{2}{*}{ Variable } & \multicolumn{2}{|l|}{ All population } & \multicolumn{2}{|c|}{ Cycles $<4$ population } & \multicolumn{2}{|c|}{ Cycles $>=4$ population } \\
\hline & OS & DMFS & OS & DMFS & OS & DMFS \\
\hline \multicolumn{7}{|l|}{ Leucopenia } \\
\hline \multicolumn{7}{|c|}{ Mild VS Absent } \\
\hline $\mathrm{HR}(95 \% \mathrm{Cl})$ & $0.70(0.57-0.86)$ & $0.79(0.63-0.98)$ & $0.73(0.57-0.92)$ & $0.87(0.66-1.14)$ & $0.56(0.38-0.86)$ & $0.56(0.37-0.86)$ \\
\hline$p$ & 0.001 & 0.038 & 0.009 & 0.309 & 0.007 & 0.008 \\
\hline \multicolumn{7}{|c|}{ Severe VS Absent } \\
\hline $\mathrm{HR}(95 \% \mathrm{Cl})$ & $0.77(0.60-0.97)$ & $1.01(0.78-1.31)$ & $0.86(0.63-1.16)$ & $1.10(0.79-1.54)$ & $0.59(0.38-0.90)$ & $0.73(0.46-1.14)$ \\
\hline$P$ & 0.030 & 0.927 & 0.320 & 0.554 & 0.016 & 0.166 \\
\hline \multicolumn{7}{|c|}{ Mild VS Severe } \\
\hline $\mathrm{HR}(95 \% \mathrm{Cl})$ & $0.91(0.76-1.09)$ & $0.77(0.64-0.93)$ & 0.85(0.66-1.08) & $0.78(0.61-1.02)$ & $0.98(0.75-1.28)$ & $0.77(0.58-1.09)$ \\
\hline$p$ & 0.314 & 0.007 & 0.191 & 0.069 & 0.887 & 0.058 \\
\hline \multicolumn{7}{|l|}{ Gender } \\
\hline $\mathrm{HR}(95 \% \mathrm{Cl})$ & $0.62(0.51-0.75)$ & $0.69(0.57-0.84)$ & $0.63(0.50-0.79)$ & $0.71(0.55-0.91)$ & $0.61(0.45-0.84)$ & $0.67(0.49-0.2)$ \\
\hline$P$ & $<0.001$ & $<0.001$ & $<0.001$ & 0.007 & 0.002 & 0.015 \\
\hline \multicolumn{7}{|l|}{ Age } \\
\hline $\mathrm{HR}(95 \% \mathrm{Cl})$ & $1.84(1.59-2.14)$ & $1.09(0.93-1.27)$ & $1.93(1.59-2.34)$ & 1.14(0.94-1.39) & $1.73(1.36-2.19)$ & $1.01(0.77-1.30)$ \\
\hline$P$ & $<0.001$ & 0.304 & $<0.001$ & 0.191 & $<0.001$ & 0.941 \\
\hline \multicolumn{7}{|c|}{ T-classification } \\
\hline $\mathrm{HR}(95 \% \mathrm{Cl})$ & $1.27(1.14-1.40)$ & $1.09(0.99-1.22)$ & $1.27(1.11-1.45)$ & $1.11(0.96-1.27)$ & $1.26(1.07-1.49)$ & $1.08(0.91-1.27)$ \\
\hline$P$ & $<0.001$ & 0.092 & 0.001 & 0.157 & 0.007 & 0.375 \\
\hline \multicolumn{7}{|c|}{ N-classification } \\
\hline $\mathrm{HR}(95 \mathrm{Cl})$ & $1.56(1.43-1.70)$ & $1.65(1.50-1.81)$ & $1.70(1.51-1.90)$ & $1.75(1.54-1.97)$ & $1.39(1.21-1.60)$ & $1.52(1.32-1.76)$ \\
\hline$P$ & $<0.001$ & $<0.001$ & $<0.001$ & $<0.001$ & $<0.001$ & $<0.001$ \\
\hline \multicolumn{7}{|c|}{ Radiotherapy } \\
\hline $\mathrm{HR}(95 \% \mathrm{Cl})$ & $0.80(0.68-0.94)$ & $0.91(0.76-1.08)$ & $0.88(0.70-1.10)$ & $1.03(0.82-1.30)$ & $0.69(0.54-0.89)$ & $0.75(0.58-0.97)$ \\
\hline$P$ & 0.008 & 0.273 & 0.264 & 0.764 & 0.005 & 0.030 \\
\hline
\end{tabular}

Abbreviations: OS: overall survival; DMFS: distant metastasis-free survival; HR: hazard ratio; Cl: confidence interval; ANPC: advanced nasopharyngeal carcinoma 

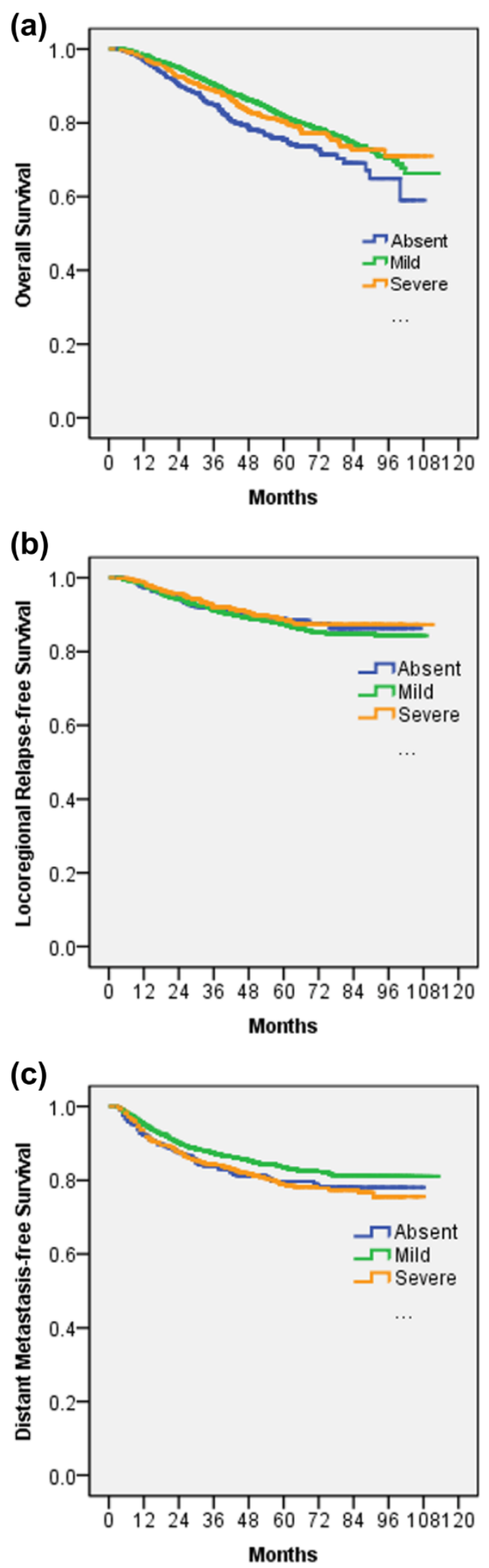

Fig. 1 Kaplan-Meier survival curves of (a) Overall Survival, (b) Locoregional Relapse-free Survival, and (c) Distant Metastasis-free Survival according to severity of leucopenia leucopenia was $88.9 \%, 87.4 \%$, and $88.6 \%$, respectively (all $p>0.05$ for any two compared groups).

We performed multivariate analysis to investigate whether leucopenia could be a marker of improved OS and DMFS (Table 3). Leucopenia and other prognostic factors, i.e., age, sex, $\mathrm{T}$ classification, $\mathrm{N}$ classification, pathological type, type of chemotherapy, paclitaxel use, and type of RT were included in the multivariate analysis, which determined that leucopenia, sex, $\mathrm{T}$ classification, and $\mathrm{N}$ classification were independent prognostic factors for OS and DMFS. Compared to patients without leucopenia, the hazard ratios (HRs) of death for patients with mild and severe leucopenia were 0.69 [95\% confidence interval $(95 \% \mathrm{CI})$ $0.56-0.85, p<0.001]$ and 0.75 (95\% CI 0.59-0.95, $p=0.019$ ), respectively. The HR of distant metastasis for patients with mild and severe leucopenia were 0.77 (95\%CI 0.61-0.96, $p=0.023)$ and 0.99 (95 \%CI 0.77-1.29, $p=0.995)$, respectively. When we compared patients with mild leucopenia to patients with severe leucopenia, the HRs of death and distant metastasis were 0.93 (95\%CI 0.77-1.11, $p=0.416$ ) and 0.77 (95\%CI 0.64-0.93, $p=0.006)$, respectively.

When pretreatment leukocyte count $\left(\leq 10 \times 10^{9} / \mathrm{L}\right.$ vs. $\left.>10 \times 10^{9} / \mathrm{L}\right)$ was included in the Cox model, leucopenia remained significant for OS (mild leucopenia: $\mathrm{HR}=0.70,95 \% \mathrm{CI} 0.57-0.86, p=0.001$; severe leucopenia: $\mathrm{HR}=0.76,95 \% \mathrm{CI} 0.59-0.97, p=0.026)$ and DMFS (mild leucopenia: $\mathrm{HR}=0.77$, $95 \% \mathrm{CI} 0.61-0.96, p=0.023$; severe leucopenia: $\mathrm{HR}=0.99,95 \% \mathrm{CI} 0.77-1.30, p=0.995$ ).

Tables 2 and 3 depict the subgroup analysis results for patients who received $<4$ and $\geq 4$ chemotherapy cycles. Mild and severe leucopenia tended to be associated with improved survival in patients who received $<4$ or $\geq 4$ chemotherapy cycles.

\section{Discussion}

In this study, we found that survival was improved in patients who developed leucopenia during chemoradiotherapy for ANPC. Patients with mild leucopenia had better OS and DMFS than those with severe leucopenia. Leucopenia was an independent prognostic factor for OS and DMFS in patients who received $<4$ and $\geq 4$ chemotherapy cycles. This is the first instance that has been reported in pretreated ANPC.

As far as we know, leucopenia or neutropenia indicates that the chemotherapeutic agent dose is sufficient to cause bone marrow suppression and an anti-tumor effect $[8,9]$. The absence of leucopenia or neutropenia indicates an absent or weak biological effect of chemotherapy, likely indicating that the dose is too low. On the other hand, severe leucopenia may indicate overdosage. High-dose chemotherapy does not improve survival, and impairs patient quality of life [28]. We speculate that moderate-dose chemotherapy, as evidenced by moderate toxicity, is the optimal treatment, correlating with better survival than 
Table 3 Multivariate analysis of survival for patients with ANPC

\begin{tabular}{|c|c|c|c|c|c|c|}
\hline \multirow[b]{2}{*}{ Variable } & \multicolumn{2}{|l|}{ All population } & \multicolumn{2}{|c|}{ Cycles $<4$ population } & \multicolumn{2}{|c|}{ Cycles $>=4$ population } \\
\hline & OS & DMFS & OS & DMFS & OS & DMFS \\
\hline \multicolumn{7}{|l|}{ Leucopenia } \\
\hline \multicolumn{7}{|c|}{ Mild VS Absent } \\
\hline $\mathrm{HR}(95 \% \mathrm{Cl})^{\mathrm{a}}$ & $0.69(0.56-0.85)$ & $0.77(0.61-0.96)$ & $0.70(0.55-0.89)$ & $0.88(0.63-1.23)$ & $0.73(0.46-1.15)$ & $0.61(0.40-0.94)$ \\
\hline$P$ & $<0.001$ & 0.023 & 0.003 & 0.452 & 0.174 & 0.025 \\
\hline \multicolumn{7}{|c|}{ Severe VS Absent } \\
\hline $\mathrm{HR}(95 \% \mathrm{Cl})^{\mathrm{a}}$ & $0.75(0.59-0.95)$ & $0.99(0.77-1.29)$ & $0.82(0.60-1.11)$ & $0.79(0.61-1.03)$ & $0.97(0.74-1.27)$ & $0.84(0.53-1.32)$ \\
\hline$P$ & 0.019 & 0.995 & 0.204 & 0.083 & 0.828 & 0.446 \\
\hline \multicolumn{7}{|c|}{ Mild VS Severe } \\
\hline $\mathrm{HR}(95 \% \mathrm{Cl})^{\mathrm{a}}$ & $0.93(0.77-1.11)$ & $0.77(0.64-0.93)$ & 0.85(0.66-1.09) & 0.90(0.68-1.19 & $0.71(0.46-1.07$ & $0.73(0.56-0.96)$ \\
\hline P & 0.416 & 0.006 & 0.204 & 0.469 & 0.108 & 0.026 \\
\hline \multicolumn{7}{|l|}{ Gender } \\
\hline $\mathrm{HR}(95 \% \mathrm{Cl})$ & $0.67(0.55-0.81)$ & $0.70(0.58-0.86)$ & $0.66(0.52-0.84)$ & $0.73(0.57-0.93)$ & $0.66(0.48-0.91)$ & $0.68(0.49-0.94)$ \\
\hline$P$ & $<0.001$ & $<0.001$ & 0.001 & 0.013 & 0.010 & 0.019 \\
\hline \multicolumn{7}{|l|}{ Age } \\
\hline $\mathrm{HR}(95 \% \mathrm{Cl})$ & $1.82(1.57-2.12)$ & 1.05(0.89-1.23) & $1.88(1.55-2.28)$ & 1.09(0.89-1.34 & $1.71(1.34-2.17)$ & $1.03(0.81-1.33)$ \\
\hline$P$ & $<0.001$ & 0.532 & $<0.001$ & 0.367 & $<0.001$ & 0.783 \\
\hline \multicolumn{7}{|c|}{ T-classification } \\
\hline $\mathrm{HR}(95 \% \mathrm{Cl})$ & $1.49(1.35-1.66)$ & 1.33(1.19-1.47) & $1.51(1.33-1.72)$ & $1.36(1.19-1.56)$ & $1.49(1.26-1.76)$ & $1.27(1.08-1.51)$ \\
\hline$P$ & $<0.001$ & $<0.001$ & $<0.001$ & $<0.001$ & $<0.001$ & 0.005 \\
\hline \multicolumn{7}{|c|}{ N-classification } \\
\hline $\mathrm{HR}(95 \mathrm{Cl})$ & $1.77(1.62-1.93)$ & $1.78(1.62-1.97)$ & $1.92(1.71-2.16)$ & $1.92(1.68-2.18)$ & $1.56(1.35-1.80)$ & $1.63(1.40-1.90)$ \\
\hline$P$ & $<0.001$ & $<0.001$ & $<0.001$ & $<0.001$ & $<0.001$ & $<0.001$ \\
\hline
\end{tabular}

Abbreviations: OS: overall survival; DMFS: distant metastasis-free survival; HR: hazard ratio; Cl: confidence interval; ANPC: advanced nasopharyngeal carcinoma ${ }^{a}$ Adjusted for age ( $<45$ and $\geq 45$ years old), sex, $\mathrm{T}$ classification $(\mathrm{T} 1 / \mathrm{T} 2 / \mathrm{T} 3 / \mathrm{T} 4), \mathrm{N}$ classification (N0/N1/N2/N3), pathological type, type of radiotherapy, type of chemotherapy, and paclitaxel use

under- or overdosage. Colleoni et al. [29] found that patients who received level II doses (65-84 \% of the prescribed dose) had longer disease-free survival (DFS) and OS than patients who received higher (level I: $>85 \%$ of the prescribed dose) or lower (level III: $<65 \%$ of the prescribed dose) doses $(p=0.07, p=0.03$, respectively). Additionally, Brunetto et al. reported that there was no difference in OS for patients whose dose had been reduced compared to patients whose dose had been maintained [30]. Nakatat al. [17] and Shitara et al. [15] both found that patients with mild neutropenia had better outcomes than those with severe neutropenia; others have reported that patients who developed grade 2-3 leucopenia or neutropenia had significantly better prognosis than those with grade 4 leucopenia or neutropenia [16, 17, 31]. Our results agree with these results. In other words, mild leucopenia or neutropenia might be a barometer of the appropriate chemotherapeutic dosage to obtain sufficient anti-tumor effect in a patient, leading to improved clinical outcome; however, severe leucopenia or neutropenia might be a marker of overdosage and suboptimal survival.
However, there are differing findings: Kim et al. [22] reported that neutropenia was not a significant prognostic indicator of improved progression-free survival and OS $(p=0.180, p=0.698$, respectively) in stage I-IIIB breast cancer. Kumpulainen et al. [23] drew a wholly different conclusion, where the 10-year DFS in FIGO (International Federation of Obstetrics and Gynecology) stage IC-IV disease was $45 \%$ in patients with lower leukocyte counts $\left(<2.5 \times 10^{9} / \mathrm{L}\right)$ and $66 \%$ in patients with higher leukocyte counts $\left(\geq 2.5 \times 10^{9} / \mathrm{L}\right)(p<0.05)$. The probable reason is that the different disease stages might obscure the impact of leucopenia. Most studies and ours studied patients with advanced-stage disease.

Several reports have stated that pretreatment high leukocyte or neutrophil count might be a poor prognostic indicator and that leucopenia or neutropenia are less likely to occur during treatment [32, 33]. However, in our multivariate analysis, which included this factor, leucopenia remained significant for OS and DMFS.

Due to the retrospective nature of our study, there are some limitations. First, the chemotherapy regimens and 
dose varied. Second, patients were identified from 2005 to 2010, and the normal range of hematological profiles may have varied. Third, although G-CSF was not used for prophylaxis, it would nevertheless affect the severity of leucopenia. Fourth, we only analyzed leucopenia, a sign of myelosuppression. Taking hemoglobin and platelet inhibition into account might reflect the relationship between myelosuppression and prognosis more accurately.

\section{Conclusions}

Leucopenia during chemoradiotherapy of ANPC is strongly associated with better OS and DMFS; mild leucopenia indicates better survival than severe leucopenia. This may indicate that mild leucopenia is a surrogate marker for adequate chemotherapeutic dose. We can identify the patients who may benefit from chemotherapy if they experienced leucopenia during the treatment. The chemotherapy dose should not only depend on the body surface area, but also be based on its toxic effects. Prospective trials are required to assess whether dosing adjustments based on leucopenia may improve chemotherapy efficacy.

\section{Abbreviations}

ANPC: Advanced nasopharyngeal carcinoma; CRT: Conventional radiotherapy; IMRT: Intensity modulated radiation therapy; NCCN: National comprehensive cancer network; G-CSF: Granulocyte colony-stimulating factor; MRI: Magnetic resonance imaging; ECT: Emission computed tomography; CT: Computed tomography; IC: Induction chemotherapy; CC: Concurrent chemotherapy; AC: Adjuvant chemotherapy; HR: Hazard ratio; Cl: Confidence interval; OS: Overall survival; DMFS: Distant metastasis-free survival; LRFS: Locoregional relapse-free survival; DFS: Disease-free survival; FIGO: International federation of obstetrics and gynecology; WHO: World health organization.

\section{Competing interests}

The authors declare that they have no competing interests.

\section{Authors' contributions}

SZ checked data, drafted the manuscript and performed the statistical analysis. OYPU, TJ and LXW collected the data. XFY participated in the design of the study. MYP conceived of the study, and participated in its design and coordination and helped to draft the manuscript. All authors read and approved the final manuscript. Both Zhen Su and Yan-Ping Mao contributed equally to this manuscript.

\section{Acknowledgements}

This work was supported by grants from the National Natural Science Foundation of China (No. 81201746), Planned Science and Technology Project of Guangdong Province (2012B031800092), Medical Science Foundation of Guangdong Province (No. B2012135), Cultivating Foundation of Education-bureau of Guangdong Province (No. LYM11001).

Received: 16 October 2014 Accepted: 15 May 2015

Published online: 24 May 2015

\section{References}

1. Chen $L$, Mao Y, Xie F, Liu L, Sun $Y$, Tian $L$, et al. The seventh edition of the UICC/AJCC staging system for nasopharyngeal carcinoma is prognostically useful for patients treated with intensity-modulated radiotherapy from an endemic area in China. Radiother Oncol. 2012;104(3):331-7.

2. Perri F. Locally advanced nasopharyngeal carcinoma: current and emerging treatment strategies. World Journal of Clinical Oncology. 2011;2(12):377.
3. Adham M, Kurniawan AN, Muhtadi Al, Roezin A, Hermani B, Gondhowiardjo $\mathrm{S}$, et al. Nasopharyngeal carcinoma in Indonesia: epidemiology, incidence, signs, and symptoms at presentation. Chin J Cancer. 2012;31(4):185-96.

4. Peng G, Wang T, Yang KY, Zhang S, Zhang T, Li Q, et al. A prospective, randomized study comparing outcomes and toxicities of intensity-modulated radiotherapy vs. conventional two-dimensional radiotherapy for the treatment of nasopharyngeal carcinoma. Radiother Oncol. 2012;104(3):286-93.

5. Lai SZ, Li WF, Chen L, Luo W, Chen YY, Liu LZ, et al. How does intensitymodulated radiotherapy versus conventional two-dimensional radiotherapy influence the treatment results in nasopharyngeal carcinoma patients? Int J Radiat Oncol Biol Phys. 2011;80(3):661-8.

6. Baujat B, Audry H, Bourhis J, Chan AT, Onat H, Chua DT, et al. Chemotherapy in locally advanced nasopharyngeal carcinoma: an individual patient data meta-analysis of eight randomized trials and 1753 patients. Int J Radiat Oncol Biol Phys. 2006;64(1):47-56.

7. Pfister DG, Spencer S, Brizel DM, Burtness B, Busse PM, Caudell JJ, et al. Head and neck cancers, Version 2.2014. Clinical practice guidelines in oncology. J Natl Compr Canc Netw. 2014;12(10):1454-87.

8. Kvinnsland S. The leucocyte nadir, a predictor of chemotherapy efficacy? Br J Cancer. 1999:80(11):1681.

9. Gurney H. How to calculate the dose of chemotherapy. Br J Cancer. 2002;86(8):1297-302.

10. Mayers C, Panzarella T, Tannock IF. Analysis of the prognostic effects of inclusion in a clinical trial and of myelosuppression on survival after adjuvant chemotherapy for breast carcinoma. Cancer. 2001;91 (12):2246-57.

11. Poikonen P, Saarto T, Lundin J, Joensuu H, Blomqvist C. Leucocyte nadir as a marker for chemotherapy efficacy in node-positive breast cancer treated with adjuvant CMF. Br J Cancer. 1999;80(11):1763-6.

12. Saarto T, Blomqvist C, Rissanen P, Auvinen A, Elomaa I. Haematological toxicity: a marker of adjuvant chemotherapy efficacy in stage II and III breast cancer. Br J Cancer. 1997;75(2):301-5.

13. Sunaga T, Suzuki S, Kogo M, Kurihara T, Kaji S, Koike N, et al. The association between neutropenia and prognosis in stage III colorectal cancer patients receiving adjuvant chemotherapy. Eur J Cancer Care. 2013:n/a-n/a.

14. Shitara K, Matsuo K, Takahari D, Yokota T, Inaba Y, Yamaura H, et al. Neutropaenia as a prognostic factor in metastatic colorectal cancer patients undergoing chemotherapy with first-line FOLFOX. Eur J Cancer. 2009;45(10):1757-63.

15. Shitara K, Matsuo K, Takahari D, Yokota T, Shibata T, Ura T, et al. Neutropenia as a prognostic factor in advanced gastric cancer patients undergoing second-line chemotherapy with weekly paclitaxel. Ann Oncol. 2010:21(12):2403-9.

16. Yamanaka T, Matsumoto S, Teramukai S, Ishiwata R, Nagai Y, Fukushima M. Predictive value of chemotherapy-induced neutropenia for the efficacy of oral fluoropyrimidine S-1 in advanced gastric carcinoma. Br J Cancer. 2007;97(1):37-42.

17. Nakata B, Tsuji A, Mitachi Y, Yamamitsu S, Hirata K, Takeuchi T, et al. Moderate neutropenia with S-1 plus low-dose cisplatin may predict a more favourable prognosis in advanced gastric cancer. Clin Oncol-Uk. 2006;18(9):678-83.

18. Jang SH, Kim SY, Kim JH, Park S, Hwang YI, Kim DG, et al. Timing of chemotherapy-induced neutropenia is a prognostic factor in patients with metastatic non-small-cell lung cancer: a retrospective analysis in gemcitabine-plus-platinum-treated patients. J Cancer Res Clin Oncol. 2013;139(3):409-17.

19. Pallis AG, Agelaki S, Kakolyris S, Kotsakis A, Kalykaki A, Vardakis N, et al. Chemotherapy-induced neutropenia as a prognostic factor in patients with advanced non-small cell lung cancer treated with front-line docetaxel-gemcitabine chemotherapy. Lung Cancer-J laslc. 2008;62(3):356-63.

20. Di Maio M, Gridelli C, Gallo C, Shepherd F, Piantedosi FV, Cigolari S, et al. Chemotherapy-induced neutropenia and treatment efficacy in advanced non-small-cell lung cancer: a pooled analysis of three randomised trials. Lancet Oncol. 2005;6(9):669-77.

21. Klimm B, Reineke T, Haverkamp H, Behringer K, Eich HT, Josting A, et al. Role of hematotoxicity and sex in patients with Hodgkin's lymphoma: an analysis from the German Hodgkin Study Group. J Clin Oncol. 2005;23(31):8003-11.

22. Kim J, Park J, Kim D, Kim J, Kim Y, Nam J, et al. Is chemotherapy-induced neutropenia a prognostic factor in patients with ovarian cancer? Acta Obstet Gyn Scan. 2010;89(5):623-8.

23. Kumpulainen EJ, Hirvikoski PP, Johansson RT. Neutropenia during adjuvant chemotherapy of breast cancer is not a predictor of outcome. Acta Oncol. 2009;48(8):1204-6. 
24. Forastiere AA, Ang KK, Brizel D, Brockstein BE, Burtness BA, Cmelak AJ, et al. Head and neck cancers. J Natl Compr Canc Netw. 2008:6(7):646-95.

25. Forastiere AA, Ang K, Brizel D, Brockstein BE, Dunphy F, Eisele DW, et al. Head and neck cancers. J Natl Compr Canc Netw. 2005;3(3):316-91.

26. Liang SB, Sun Y, Liu LZ, Chen Y, Chen L, Mao YP, et al. Extension of local disease in nasopharyngeal carcinoma detected by magnetic resonance imaging: improvement of clinical target volume delineation. Int J Radiat Oncol Biol Phys. 2009;75(3):742-50.

27. Ma J, Liu L, Tang L, Zong J, Lin A, Lu T, et al. Retropharyngeal lymph node metastasis in nasopharyngeal carcinoma: prognostic value and staging categories. Clin Cancer Res. 2007;13(5):1445-52.

28. Brandberg Y. Quality of life in women with breast cancer during the first year after random assignment to adjuvant treatment with marrowsupported high-dose chemotherapy with cyclophosphamide, thiotepa, and carboplatin or tailored therapy with fluorouracil, epirubicin, and cyclophosphamide: scandinavian breast group study 9401. J Clin Oncol. 2003;21(19):3659-64

29. Colleoni M, Price K, Castiglione-Gertsch M, Goldhirsch A, Coates A, Lindtner $J$, et al. Dose-response effect of adjuvant cyclophosphamide, methotrexate, 5-fluorouracil (CMF) in node-positive breast cancer. International Breast Cancer Study Group. Eur J Cancer. 1998;34(11):1693-700.

30. Brunetto AT, Carden CP, Myerson J, Faria AL, Ashley S, Popat S, et al. Modest reductions in dose intensity and drug-induced neutropenia have no major impact on survival of patients with non-small cell lung cancer treated with platinum-doublet chemotherapy. J Thorac Oncol. 2010;5(9):1397-403.

31. Cameron DA, Massie C, Kerr G, Leonard RC. Moderate neutropenia with adjuvant CMF confers improved survival in early breast cancer. $\mathrm{Br} J$ Cancer. 2003;89(10):1837-42.

32. Chang H, Gao J, Xu BQ, Guo SP, Lu RB, Li G, et al. Haemoglobin, neutrophil to lymphocyte ratio and platelet count improve prognosis prediction of the TNM staging system in nasopharyngeal carcinoma: development and validation in 3237 patients from a single institution. Clin Oncol-Uk. 2013;25(11):639-46.

33. He JR, Shen GP, Ren ZF, Qin H, Cui C, Zhang Y, et al. Pretreatment levels of peripheral neutrophils and lymphocytes as independent prognostic factors in patients with nasopharyngeal carcinoma. Head Neck. 2012;34(12):1769-76.

\section{Submit your next manuscript to BioMed Central and take full advantage of:}

- Convenient online submission

- Thorough peer review

- No space constraints or color figure charges

- Immediate publication on acceptance

- Inclusion in PubMed, CAS, Scopus and Google Scholar

- Research which is freely available for redistribution 